\title{
THE DYNAMICS OF EDUCATION IN BULGARIA IN THE CONTEXT OF THE “LIFELONG LEARNING STRATEGY”
}

\author{
Radka P. Ivanova \\ Assoc. Prof. Dr., University of Economics Varna, Bulgaria, r.ivanova@ue-varna.bg
}

\begin{abstract}
Constant changes in the economic and social aspect create new conditions in which people have to live. The rapid development of technologies and their entry into all areas is a challenge to knowledge and skills, as well as a prerequisite for seeking opportunities for their development. Completion of one level of education today should rather be seen as a fulcrum for further education. Dynamic changes make it necessary to constantly increase the competencies of people, regardless of their age. Starting the work process today should be interpreted as the beginning of additional training and qualifications in order to be able to meet the constant challenges of the environment. The starting point in the National Strategy for Lifelong Learning in Bulgaria is to achieve a high level of knowledge, continuous innovation, adaptation to the changes and achieving social participation of all. Learning is associated with processes such as adaptation, knowledge, development, which should be designed and coordinated internally and externally; has its own goals, focused on the acquisition of new knowledge and experience, organization according to certain criteria and use of information. The creation of favorable conditions for creative and professional realization of people of different age groups is possible by ensuring equal access to various forms of lifelong learning, having the necessary quality characteristics. As a reason for the need for constant improvement and upgrading of the qualification - can be considered the intensive development of technologies - requiring new skills for handling them. The discrepancy between supply and demand on the labor market also implies reforming of education in Bulgaria as a whole.
\end{abstract}

The purpose of the article is to analyze the achievements in the field of education in Bulgaria in relation to the National Strategy for Lifelong Learning for the period 2014-2020 and to identify priority areas for further development.

Keywords: education, strategy, development, Bulgaria

\section{INTRODUCTION}

In response to the many challenges Bulgaria faces, arising from the need to overcome the debt financial crisis on a European and global scale, as well as the need to preserve national identity and existing cultural diversity in the implementation of cohesion policies, a Strategy for Lifelong learning is developed. It covers the relationships between all participants in this process, namely learners; training providers; employers, branch organizations, trade unions, civil society organizations and other partners; regional town halls, municipalities and local communities; state bodies such as ministries and agencies regulating policies in the field. The main goal of the Strategy is to achieve smart, sustainable and inclusive growth. In this regard, the various forms of education, training and learning are covered, namely: formal, informal and self-directed. During the different stages of their life, each person goes through them in order to improve. The implementation of various forms of teaching and learning, adequate support measures, transparency and comparability, guaranteeing a certain quality, are of key importance for achieving the goals of the Lifelong Learning Strategy. 


\section{THE STRATEGY FOR LIFELONG LEARNING AND QUALITY OF EDUCATION IN BULGARIA}

\subsection{Lifelong Learning - a Means to Improve the Competitiveness of The Human Resources in Bulgaria}

The National Strategy for Lifelong Learning in Bulgaria for the period 2014-2020 is focused on quality, equality, diversity, decentralization, cooperation, flexibility; transforming vocational education and training into an effective learning opportunity that is attractive to everyone. Attention is focused on creating the necessary prerequisites for improving the suitability of graduates of vocational education and training. Fostering initiative and entrepreneurship is the key to the competitiveness of the workforce. The organization of courses, internships, etc. at the workplace, as well as in specialized centers for continuing vocational training are a prerequisite for continuous training of staff and creating favorable conditions for its better implementation in the labor market.

The analysis made regarding the implementation of the National Strategy for Lifelong Learning in Bulgaria for the period 2014-2020 show that by 2020 the conditions for equal access to education have been improved in the country, a favorable environment for the creative and professional realization of human resources through diverse forms of lifelong learning with high quality teaching and learning has been created. (https://eacea.ec.europa.eu/national-policies/eurydice/content/lifelong-learning-strategy-12_en). The main focus is the acquisition of key competencies by transforming the acquired skills among learners. Along with the achievement of functional literacy, literacy in the field of mathematics and natural sciences and foreign language skills, special attention is already paid to obtaining adequate to the new conditions technological and digital literacy. The changing reality in which the world must exist and evolve from the beginning of 2020 due to the outbreak of the pandemic has necessitated transformations in all areas and activities, which is why the possession of technological and digital skills is a priority today. Young people are privileged due to the fact that they learn much faster and easier how to use new technologies. However, this is not the case with part of the elderly population in working age, which faces a number of difficulties in meeting the new challenges. That is why it is important to continuously train and improve qualifications, including the acquisition of new skills and competencies. Accordingly, the Lifelong Learning Strategy considers adult education and training as a tool to improve the qualification level of both the employed and the unemployed and to create opportunities for their easier and timely adaptation to the dynamic development of the environment.

\subsection{Analysis of the Quality of Education in Bulgaria}

The quality of the workforce is directly dependent on the education received, the subsequent qualification and retraining of the staff, additional courses, trainings, specializations. The implementation of the Lifelong Learning Strategy presupposes fostering trust in the educational institutions from an early age, subsequent upgrading, increasing the requirements for the taught knowledge and skills, striving for self-learning. The attitude of the population to these factors is decisive for the attendance of the educational establishments, as well as for their quality. In this regard, we will first point out that in accordance with the analysis of data from the National Statistical Institute (NSI), it can be concluded that in Bulgaria there is a decrease in the number of students and school dropout level for the period 2014-2020. (See Fig. 1).

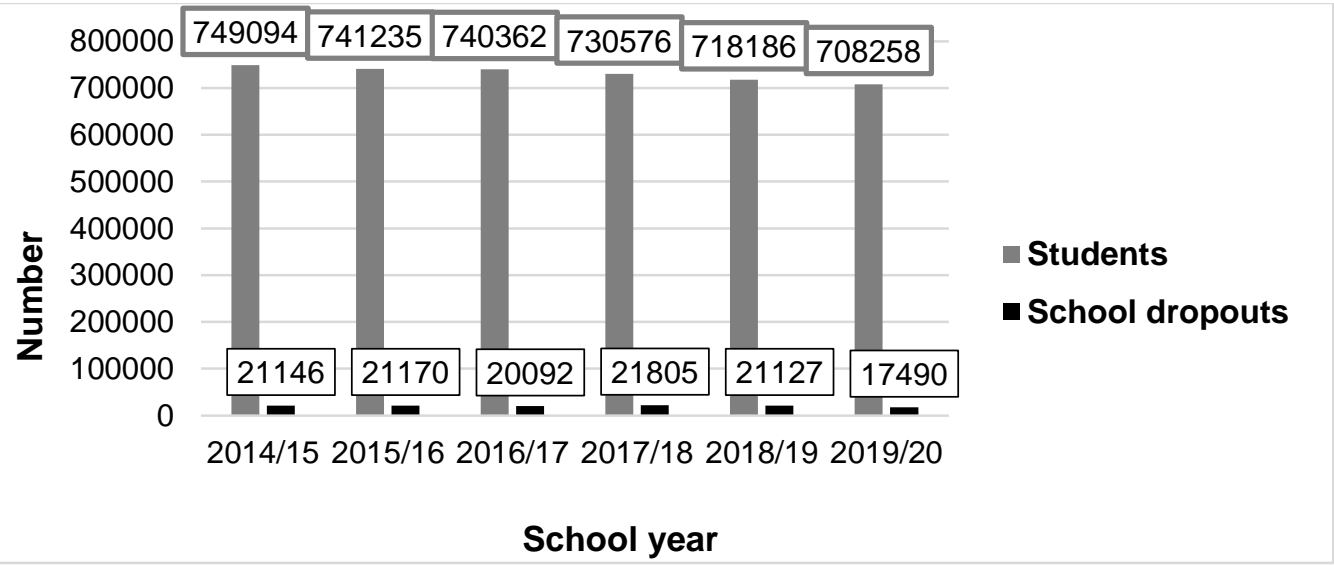

Figure 1: Number of students and school dropouts in Bulgaria (2014-2020). 
The reported decrease for students is $5.5 \%$ for the school year 2019/20 compared to 2014/15. For those who dropped out - this percentage is $17.3 \%$, which should rather be considered as a positive trend, as it shows a decrease in their share. Tracking the data on individual levels of education allows us to conclude that among those who left the educational institutions from first to seventh grade is the smallest share of those who left due to unwillingness to go to school, followed by those who left due to family reasons, and the largest share is the one of those who have gone abroad. The consecutive grades - vocational schools after $7^{\text {th }}$ grade, $8^{\text {th }}-12^{\text {th }}$ grade and the vocational colleges with admission after secondary education there is no straightforward trend.

In structural terms, in terms of levels of education during the period under review, the largest number of students is in $8^{\text {th }}-12^{\text {th }}$ grade, followed by that of students from $1^{\text {st }}$ to $4^{\text {th }}$ grade. An increasing trend is observed among the students in vocational schools after $7^{\text {th }}$ grade in the amount of 2.8 times higher in 2019/20 compared to 2014/15.

Among the students who dropped out in $8^{\text {th }}-12^{\text {th }}$ grade in the first half of the period, most are those from $5^{\text {th }}$ $-7^{\text {th }}$ grade, afterwards for 2017-2020 their number began to decrease, with the leading place being occupied by the students from $8^{\text {th }}-12^{\text {th }}$ grade who leave school.

In the field of higher education for the period 2015-2021 there is also a decline in the number of students, which can be seen as a consequence of the smaller number of students graduating from secondary education. This decrease amounts to $15.5 \%$ in the academic year 2020/21 compared to 2015/16. Most students study in the Bachelor's degree, followed by those in the Master's degree. The share of students in the Professional Bachelor's degree is the lowest (see Fig. 2).

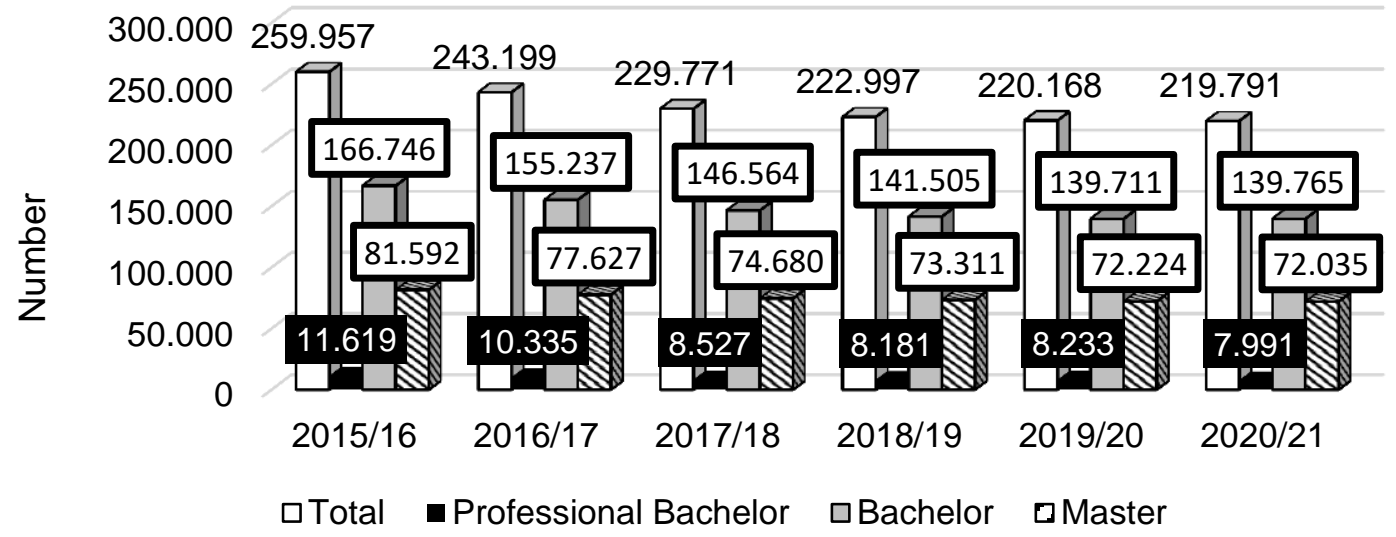

Figure 2: Distribution of students by educational qualification degrees in Bulgaria (2015-2021)

The preferred form of education is full-time, followed by part-time education. 5\% of students in $2015 / 16$ and only $4 \%$ in 2020/21 transfer to distance learning (see Fig. 3).

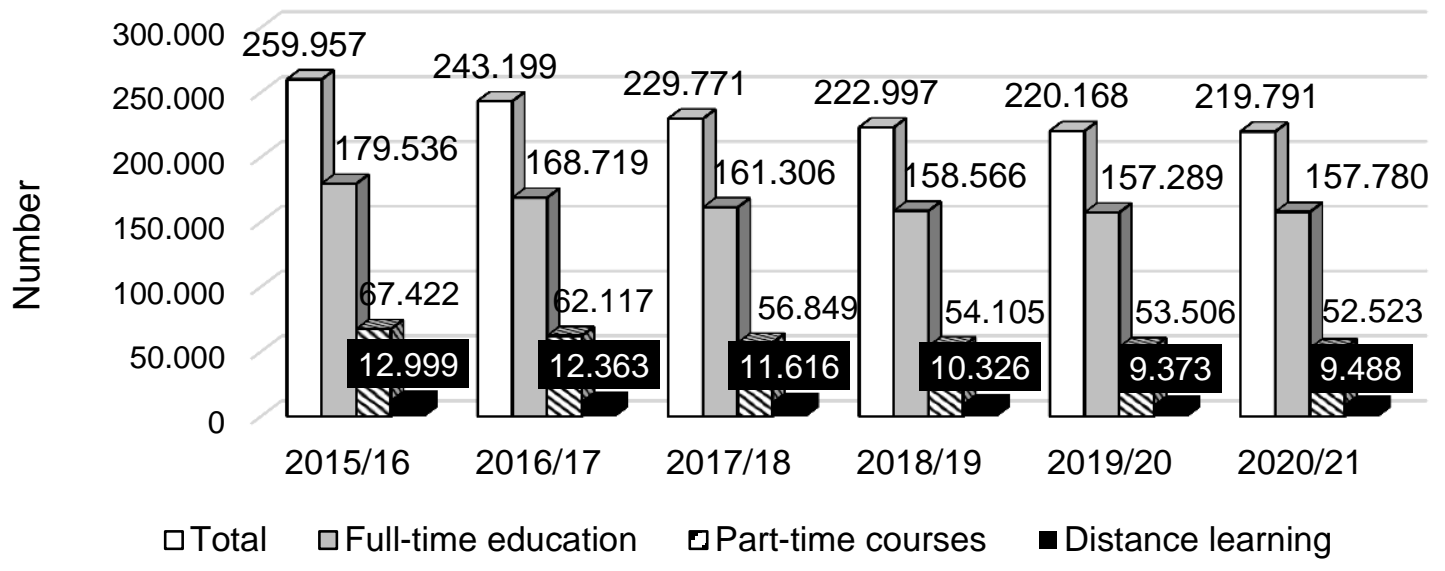

Figure 3: Distribution of students according to the form of education in Bulgaria (2015-2021) 
According to the citizenship of students, Bulgarian students predominate, whose share is almost $65 \%$ of all students, falling to $64 \%$ in $2020 / 21$. At the same time, a favorable trend is observed among foreign students, namely - their increase is 1.5 times in 2020/21 compared to 2015/16 (see Figure 4). This can be seen as an excellent evaluation of the quality of education in Bulgarian universities.

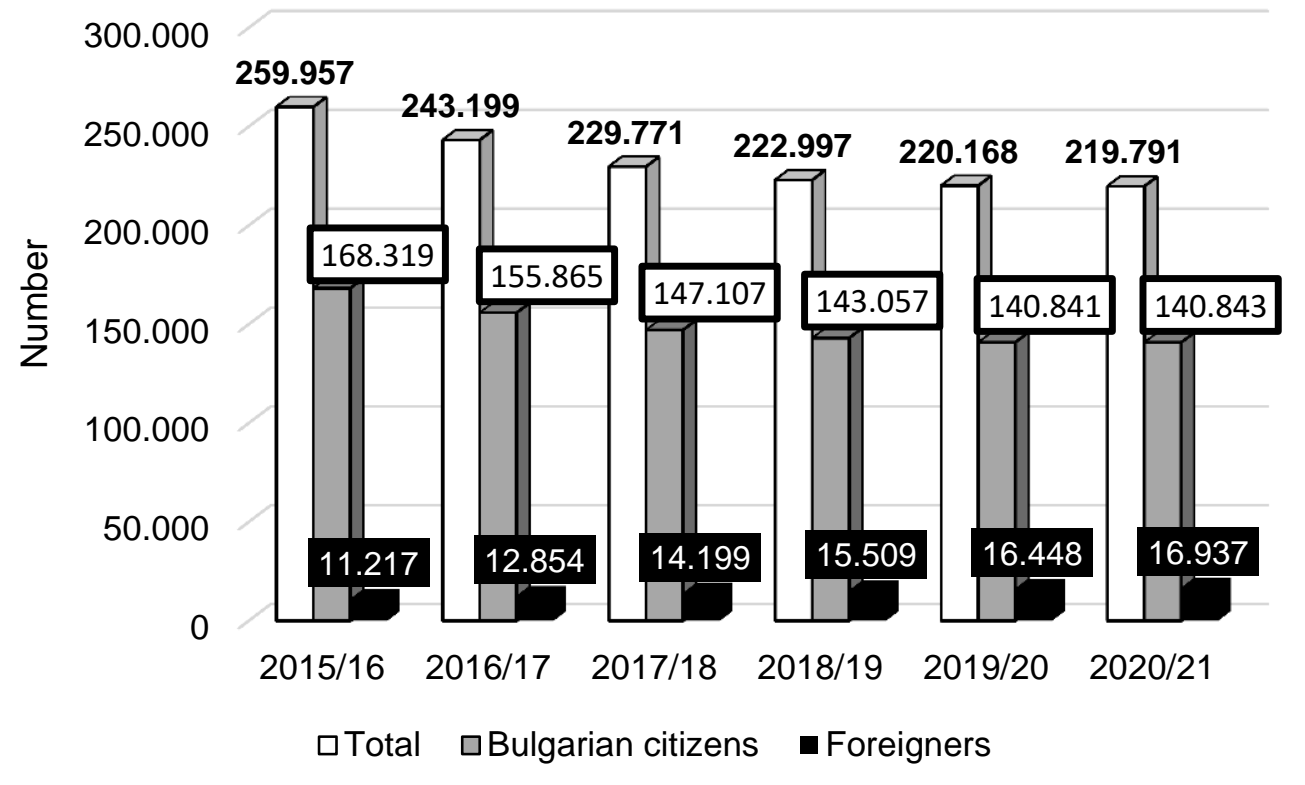

Figure 4: Distribution of students in Bulgaria according to their citizenship (2015-2021)

Following the data on the graduates of higher education, the decreasing trend is also impressive, as in 2020 their number is $26 \%$ lower than in 2015 . The least number of students received the educational and scientific degree "Doctor", as the decrease in them amounts to $24 \%$ for the period taken into review. The number of those who received a Bachelor's degree was lower by $32 \%$, by $27 \%$ at the Bachelor's degree and by $25.8 \%$ at the Master's degree (See Fig. 5).

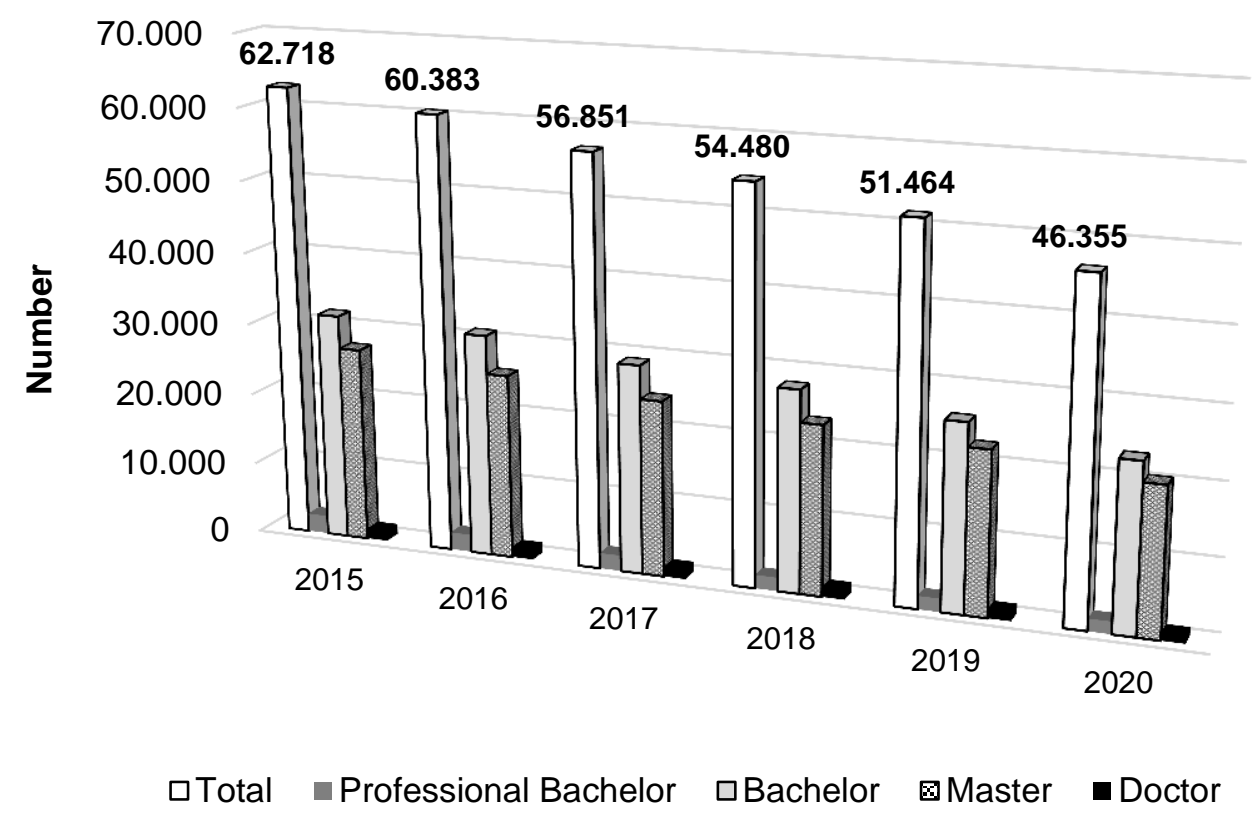

Figure 5: Graduates of higher education in Bulgaria by educational qualification degrees (2015-2020)

The highest growth rate from 2015 to 2021 is characterized by the net population ratio in lower secondary and secondary education (grades $5^{\text {th }}-7^{\text {th }}$ and $8^{\text {th }}-12^{\text {th }}$ ), namely by 6 points. An increase, although on a 
much smaller scale, is observed in the net enrollment ratio in the field of higher education (1 point), as well as in the net enrollment rate in vocational training after secondary education (0.02 points). In pre-school and primary education, the net enrollment ratio is characterized by a decline (see Fig. 6). The reasons for this can be found in the reduced birth rate in Bulgaria and the negative birth rates.

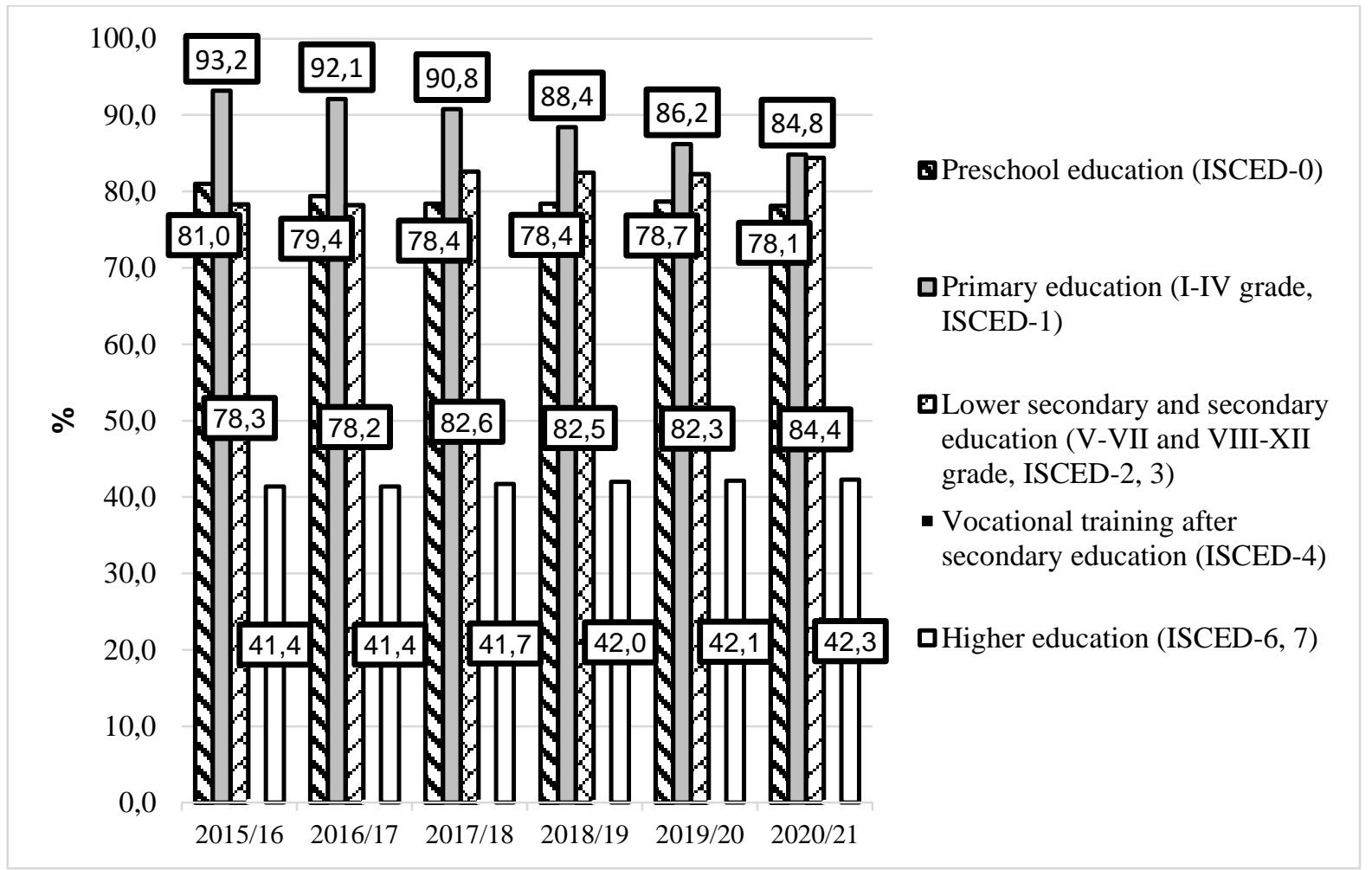

Figure 6: Dynamics of the net population ratio in Bulgaria by levels of education (2015-2021)

At the same time, in the context of the Lifelong Learning Strategy, special attention is paid to the raising of the qualifications of employees through continuing vocational training (CVT). In this regard, the follow-up of data on enterprises providing such training shows that in 2015 they increased by $13.5 \%$ compared to 2005 and by $11.1 \%$ compared to 2010 . The courses provided are internal and external, as well as other forms of continuing vocational training (see Fig. 7).

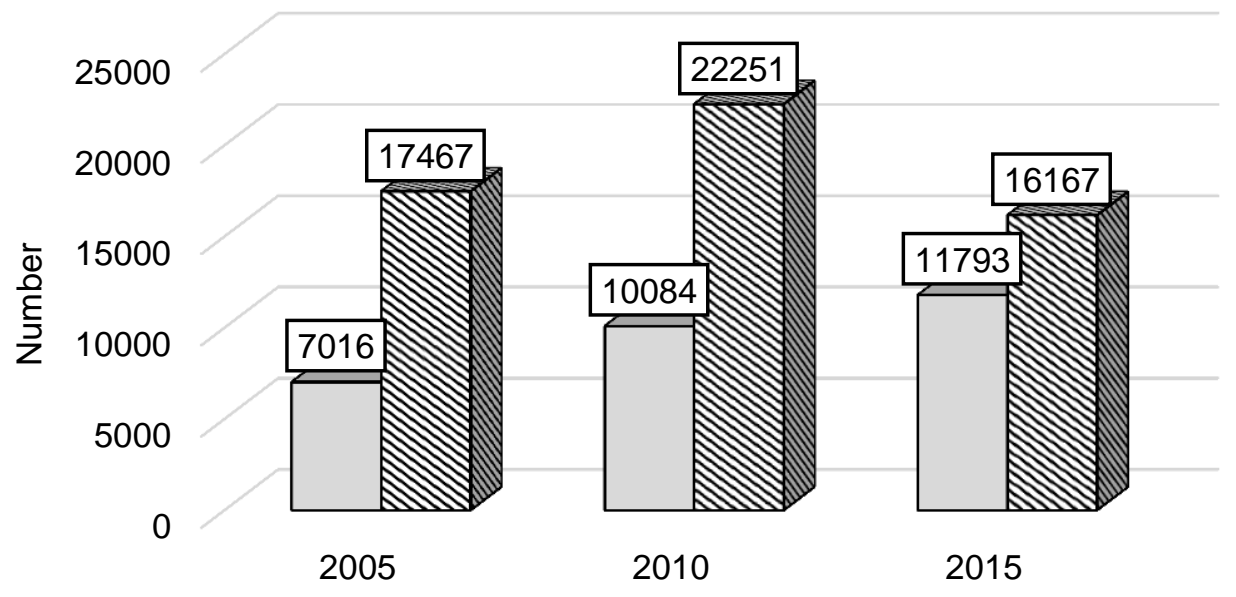

$\square$ Enterprises that do provide training $\square$ Enterprises that do not provide training

Figure 7: Enterprises providing and not providing continuing vocational training in Bulgaria (2005-2015) The analysis of the provided trainings also shows that the external CVT courses are preferable than the 
internal ones. The share of other forms of CVT remains the largest (see Fig. 8).

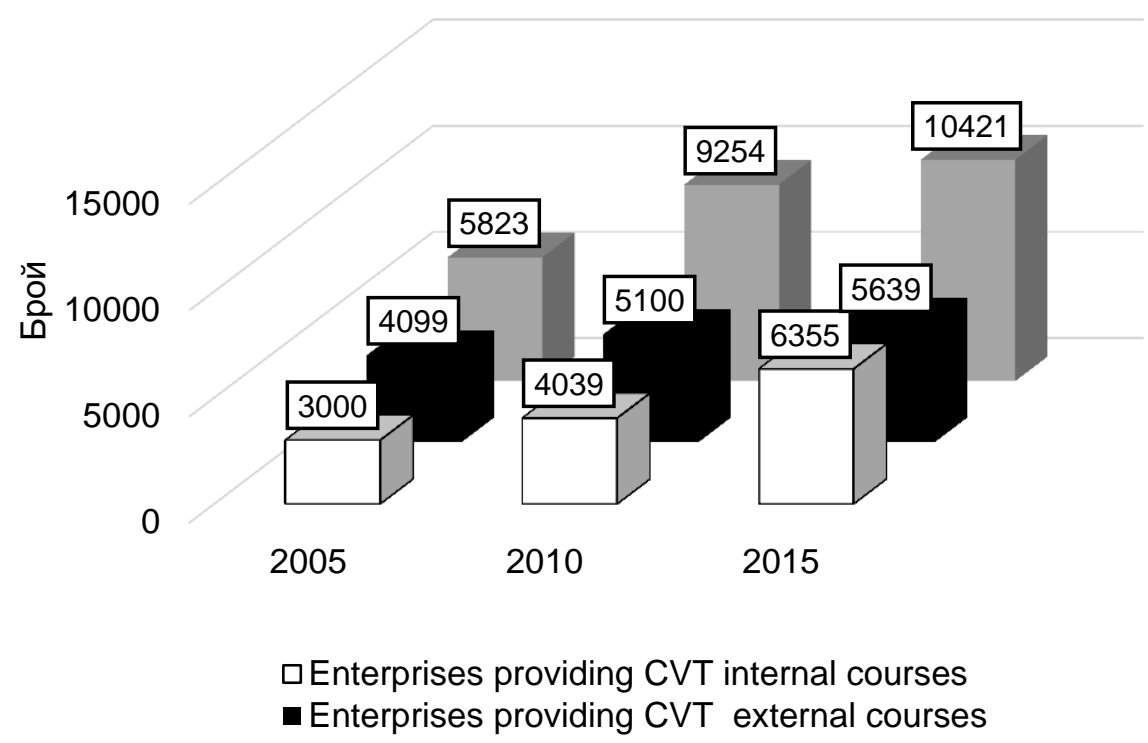

Figure 8: Provided forms for continuing vocational training in enterprises in Bulgaria (2005-2015)

Among the offered forms of CVT are training and rotation in the workplace, exchanges for training purposes, participation in conferences, workshops, exhibitions, as well as participation in training or qualification groups, as well as self-training. In each of these trainings, a favorable growing trend from 2005 to 2015 is reported (see Fig. 9).

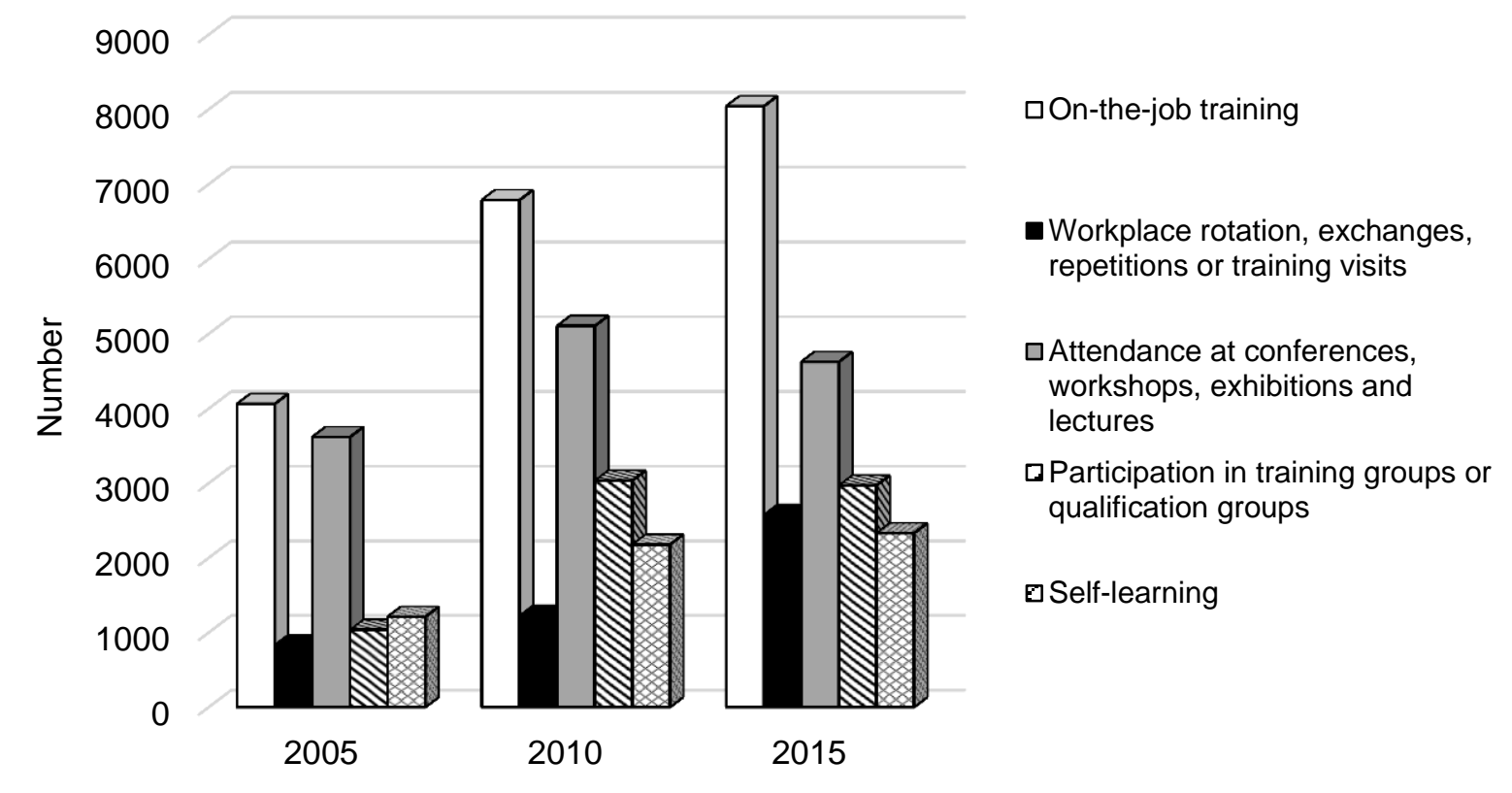

Figure 9: Distribution of the main forms of continuing vocational training in Bulgaria (2005-2015)

From the point of view of the gender structure of the participants in the organized courses, we must point out that in 1999 and 2005 the number of male students prevailed. In the following years, however, their relative share began to decrease gradually, from $71.7 \%$ in 1999 to $58.8 \%$ in 2015 of all participants in the courses and trainings conducted in the organizations (see Fig. 10). 


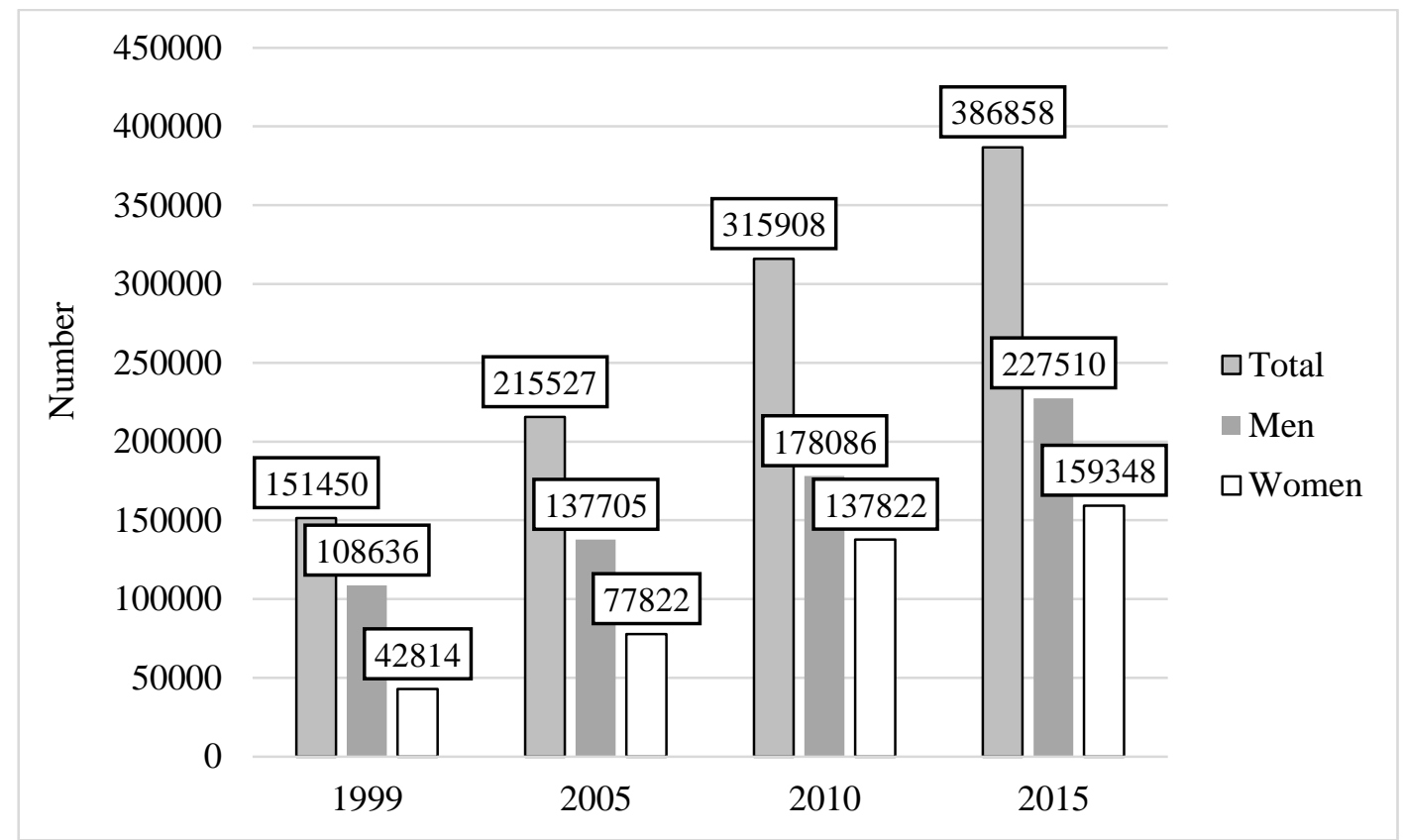

Figure 10: Distribution of the participants in CVT by gender in Bulgaria (1999-2015)

Those who have acquired a degree of professional qualification, in the centers for continuing education (VTC) for the period 2011-2020, by degrees - shows dynamics that are not straightforward. During the first three years of the period (2011-2013) there is a growing trend, followed by a decline over the next three years (2014-2016). In 2017 and 2018 again the number of acquired new degrees from I to IV degree increases, but nevertheless their total number remains below that of 2012. The last two years of the period under review - 2019 and 2020 - are again characterized by a decreasing trend, as in 2020 the lowest value, for the whole 10-year period analyzed, is reported. The largest is the number of I degree acquired, followed by the one with III degree, and the smallest - with IV degree acquired (see Fig. 11).

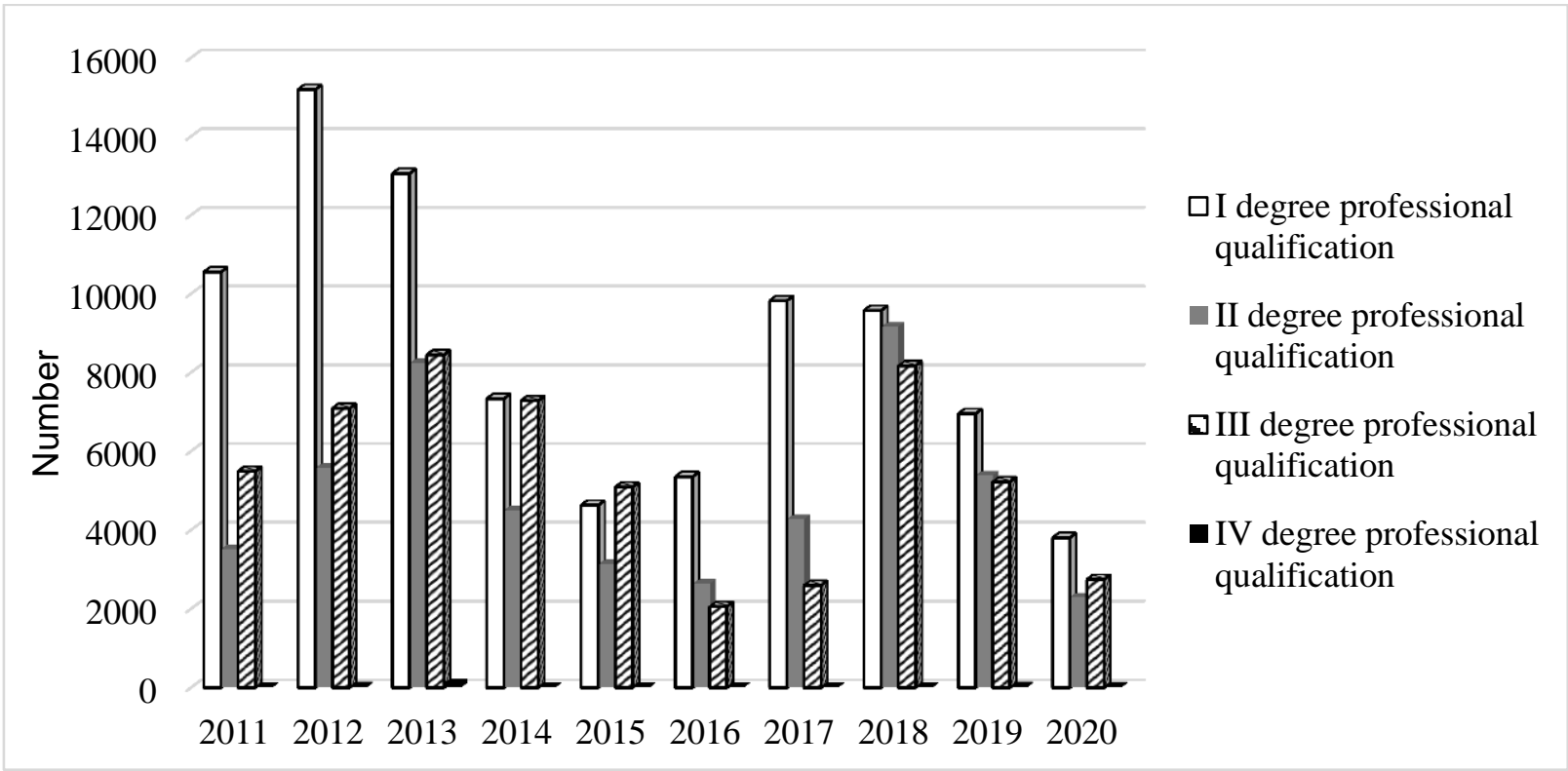

Figure 11: Acquired degrees for professional qualification in Bulgaria (2011-2020)

The reason for such reduced interest in the IV degree of professional qualification we could find, on one hand - in its higher complexity - as this degree is associated with the acquisition of professions that involve a complex nature and work in constantly changing conditions, responsibilities related to people management and resource allocation in general. On the other hand, the required minimum level of education is secondary education. In the general case, those for whom this level is not sufficient focus more on the field of higher 
education and, to a very small extent, on professional qualifications. At lower levels (I-III) it is possible to receive primary or secondary education in case it is not acquired in time (i.e. after reaching the age of 16) and this makes them significantly more attractive.

\section{ACKNOWLEDGEMENT}

Dealing with the challenges of the 21st century requires the modern man to be well educated, knowledgeable and capable in order to have prospects for both personal and social well-being. Training in its various forms can be seen as a tool that will help society cope with the intense pace and diversity of processes in all areas. The skills and qualities that people today must have are constantly changing and this requires their constant development. The leading place is occupied by the formation of values and behavior, allowing success and well-being in the personal and social aspects. This, in turn, implies a change in the way of teaching and, respectively, the acquisition of knowledge and skills, allowing the construction of appropriate values and attitudes. Particularly useful in this regard are the interactive teaching methods, active collaboration between the participants in the educational and training process, respectively personalization of the learning content and all this should be oriented towards achieving concrete results. Attracting more people in the training courses for additional qualification and retraining will allow improving the educational characteristics of the country's population, it will improve its skills and abilities, and it will increase its competitiveness. All this is to the benefit of the organizations as a whole, given the fact that they will have access to better and more capable employees. The artificial intelligence and digitalization are leading to transformation of professions and creation of new ones, which requires the improvement of digital knowledge, adaptive skills and flexibility. All this makes it necessary to use various tools to continuously encourage people to follow the strategy of lifelong learning.

\section{REFERENCE LIST}

Law on vocational education and training. State Gazette, issue 21, 13.03.2020, Bulgaria

Strategic framework for the development of education, training and learning in the Republic of Bulgaria (2021-2030). Ministry of Education and Science, Sofia

https://eacea.ec.europa.eu/national-policies/eurydice/content/lifelong-learning-strategy-12_bg [Accessed 05/11/2021].

https://nsi.bg [Accessed 10/10/2021]. 